\title{
A macrocyclic polyamine as an anion receptor in the capillary electrochromatographic separation of carbohydrates
}

\author{
Chuen-Ying Liu*, Tse-Hsien Chen, Tarun Kumar Misra \\ Department of Chemistry, National Taiwan University, Taipei, Taiwan \\ Received 22 January 2007; received in revised form 21 March 2007; accepted 22 March 2007 \\ Available online 28 March 2007
}

\begin{abstract}
An analytical approach of the 32-membered macrocyclic polyamine, 1,5,9,13,17,21,25,29-octaazacyclodotriacontane ([32] ane- $\left.\mathrm{N}_{8}\right)$ was described for the capillary electrochromatographic (CEC) separation of derivatized mono- and disaccharides. The column displayed reversal electroosmotic flow (EOF) at $\mathrm{pH}$ below 7.0, while a cathodic EOF was shown at $\mathrm{pH}$ above 7.0. The reductive amination of saccharides was carried out with $p$-aminobenzoic acid. Some parameters that affect the CEC separations were investigated. Several competitive ligands, such as Tris, EDTA and phosphate were also examined for the effect on the performance. We achieved a complete separation of all compounds as well as the excess derivatizing agent by using borate buffer ( $\mathrm{pH} 9.0$ ) in a mode of concentration gradient ( $60 \mathrm{mM}$ inlet side and $70 \mathrm{mM}$ outlet side). The relative standard deviation of the retention time measured for each sample was less than $4 \%$ in six continuous runs, suggesting that the bonded phase along with the gradient formed inside the column was quite stable. With the mixing modes of anion coordination, anion exchange, and shape discrimination, the interaction adequately accomplishes the separation of carbohydrates which are epimers or have different glycosidic linkage, although the electrophoretic migration is also involved in the separation mechanism.
\end{abstract}

(C) 2007 Elsevier B.V. All rights reserved.

Keywords: Macrocyclic polyamine; Anion coordination; Carbohydrate; Capillary electrochromatography; Fluorometric detection

\section{Introduction}

The binding and recognition of anions by synthetic macrocyclic receptors have received considerable interest in recent years [1-3]. Although such receptors have been known for several decades, the structural diversity exhibited by this class of molecules that recognize anions is not as varied as has been demonstrated for cation receptors. Complexing properties of macrocyclic receptors depend mainly on the type and arrangement of binding sites, the size and shape of the macroring and its rigidity $[4,5]$. Experimental studies on the influence of these factors on anion recognition were focused on highly charged, multiply protonated polyazamacrocyclic compounds that bind anions in protic solvents mainly through coulombic interactions. Hydrogen bonding, being more directional, is also more sensitive to geometric constraints [6].

\footnotetext{
* Corresponding author at: Department of Chemistry, National Taiwan University, 1, Sec. 4, Roosevelt Road, Taipei 10617, Taiwan. Tel.: +8862 33661645; fax: +886223638543.

E-mail address: cyliu@ ntu.edu.tw (C.-Y. Liu).
}

Synthetic carbohydrate receptors could be used as drugs to target certain cell types, to transport saccharides or related pharmaceuticals across the cell membranes or as carbohydrate sensors. Cudic and Addo-Mensah [7] have synthesized macrocyclic receptors based on 1,8-naphthyridine units bridged with positively charged polyamines and studied the stability constants of these receptors with a variety of mono- and disaccharides. Accommodation of sugars in the alkylated product of octaazamacrocyclic compounds in apolar organic media has been investigated by Kobayashi et al. [8], where the host could be regarded as a unimolecular reversed micelle. Aoyama et al. [9] have also studied the recognition of sugars via hydrogen bonding interaction with the synthetic polyhydroxy macrocycle resorcinol.

Carbohydrate chemistry is much more complex than that of either proteins or nucleic acids, and as a result, has received much less attention. The analysis of carbohydrate represents a particular challenge to capillary electrophoresis $[10,11]$ or microchip electrophoresis [12] in that most carbohydrates possess no readily ionizable groups or chromophores. Indirect detection at high $\mathrm{pH}$, borate complexation [13] or separation of charged carbohy- 
drate derivatives [14] is often suggested besides the detection with amperometry [15,16], chemiluminescence [17] or mass spectrometry [18-21]. For these indirect methods, a derivatization must be performed prior to analysis or in-column. The retention of some nitrophenyl derivatives of mono- and oligosaccharides has been studied on the $\mathrm{CN}-\mathrm{OH}$ monolith by Allen and El Rassi [22]. Fluorescence derivatization of carbohydrates often results in detection limits superior to other methods [23].

Capillary electrochromatography (CEC) is a hybrid method that combines the high selectivity of high performance liquid chromatography and the high efficiency of capillary electrophoresis. In CEC, both mobile phase and analytes are transported towards the detector by electroosmotic flow (EOF). There are several ways of incorporating stationary phases into capillaries, whose formats include packed, monolithic, and open-tubular columns. The selectivity is controlled by appropriate interactions between analytes and stationary phase during the run. CEC as one of the most efficient separation techniques was successfully applied to carbohydrate analysis [13,24-26].

We have demonstrated that 24- and 28-membered macrocyclic polyamines are highly selective as the receptor for anions such as oxyanions, polycarboxylates and polyphosphates in the CEC separation [27-35]. This highly selective property has been attributed to anion coordination, anion exchange, and reversal of the EOF provided by the wall-bonded functional groups. Super-complex formation resulting from the second sphere interaction between metallocyanide and the polyamine has also been observed [28]. The macrocyclic polyamine is a highly promising ligand, however, the synthesis is usually more difficult than it appears in print [3]. Recently, we proposed a convenient modified short route for the preparation of 32-membered macrocylic polyamine [36]. These compounds are expected to exhibit high affinity and good selectivity not only for neutral guest molecules but also for greater ionic radii of anionic guest molecules. Using the 32-membered macrocyclic polyamine incorporated onto the inner wall of a fused silica column, we examined the molecular recognition of saccharides derivatized through reductive amination by CEC with fluorometric detection.

\section{Experimental}

\subsection{Chemicals}

All chemicals were of analytical reagent grade from Merck (Darmstadt, Germany), unless otherwise stated. Purified water $(18 \mathrm{M} \Omega \mathrm{cm})$ from a Milli-Q water purification system (Millipore, Bedford, MA, USA) was used to prepare all solutions. Phosphoric acid, sodium phosphate monobasic, dibasic and tribasic (TCI, Tokyo, Japan), dimethyl sulfoxide, 2-deoxy-Dribose, D-glucose, D-xylose, D-galactose, D-mannose, cellobiose, melibiose, and maltose (Sigma, St. Louis, MO, USA), sodium cyanoborohydride, $p$-aminobenzoic acid and acetic acid (Acros, Belgium) were purchased as indicated.

All solvents and solutions for CEC analysis were filtered through a $0.45 \mu \mathrm{m}$ PTFE (Millipore) or cellulose acetate membrane (Whatman, Middlesex, UK).

\subsection{Apparatus}

All experiments were carried out in a laboratory-built unit, consisting of an intelligent fluorescence detector (model FP1520 , Jasco, Japan) and a $\pm 30 \mathrm{kV}$ high voltage power supply (Gamma High Voltage Research Inc., Ormond Beach, FL, USA). Electrochromatograms were recorded and processed with a Peak-ABC Chromatography Workstation Ver. 2.11 (Jiteng Trading, Singapore) running on Window XP operating system. Fused silica capillaries (Polymicro Technologies, Phoenix, AZ, USA) with an i.d. of $75 \mu \mathrm{m}$ and an o.d. of $375 \mu \mathrm{m}$ were used.

\subsection{Preparation of 32-membered macrocyclic polyamine} [36]

Preparatory steps are given in Fig. 1. The preparation started with the tosylation of tetramine, $N, N^{\prime}$-bis (3-aminopropyl)1,3-propanediamine which is commercially available in a reasonable price, affording $N, N^{\prime}-4,8$-tetra( $p$-toluenesulfonyl)4,8-diazaundecane-1,11-diamine (1) in 84\% yield. Alkylation of compound $\mathbf{1}$ on the terminal tosylated-N with 3-chloro-1-propanol in DMF at $110^{\circ} \mathrm{C}$ gave 4,8,12,16-tetra( $p$ toluenesulfonyl)-4,8,12,16-tetraazanonadecane-1,19-diol (2) in $66 \%$ yield. The two hydroxyl groups in diol 2 , were further converted to facile leaving groups with methanesulfonylchloride $(\mathrm{MsCl})$ to give 1,19-di(methanesulfonyl)-4,8,12,16-tetra( $p$ toluenesulfonyl)-4,8,12,16-tetraazanonadecane (3) with an isolated yield of $97 \%$. Compound $\mathbf{3}$ was then subjected for the final cyclization with the dianion of compound 1. As a result, tosylated cyclic 32-membered, [32]ane$\mathrm{N}_{8}(\mathrm{Ts})_{8}$ (4) was obtained in $45 \%$ yield. Detosylation of (4) with $33 \% \mathrm{HBr}-\mathrm{AcOH} / \mathrm{PhOH}$ at $80^{\circ} \mathrm{C}$ provided the bromide salt of $1,5,9,13,17,21,25,29$-octaazacyclodotriacontane. Passage through anion exchanger resin Dowex $1 \mathrm{X} 8 / \mathrm{Cl}^{-}$gave the chloride salt of 32-membered macrocyclicpolyamine, [32]ane$\mathrm{N}_{8} \cdot 8 \mathrm{HCl}(\mathbf{5})$, with a yield of $82 \%$.

\subsection{Preparation of macrocyclic polyamine bonded phase capillary column}

After pretreatment with $\mathrm{NaOH}(1 \mathrm{M}), \mathrm{HCl}(1 \mathrm{M})$ and pure water, the bare fused silica capillaries were purged with nitrogen $(20 \mathrm{~min})$, and then dried at $110^{\circ} \mathrm{C}$ overnight. For coating, a capillary washing kit was used to fill the capillary with a $10 \%(\mathrm{w} / \mathrm{v})$ solution of $\gamma$-glycidoxypropyltrimethoxysilane in toluene under $30 \mathrm{psi}$ pressure for $20 \mathrm{~min}$. The capillary was kept for $12 \mathrm{~h}$ at $110^{\circ} \mathrm{C}$ for silylization. After purging with toluene $(30 \mathrm{~min})$ to remove unreacted reagent, the capillaries were dried in a vacuum oven $(20 \mathrm{~min})$. The capillary was then filled with a $1 \%(w / v)$ solution of the macrocyclic compound, [32]ane$\mathrm{N}_{8} .8 \mathrm{HCl}$ in $N, N$-dimethylforamide. After standing for $24 \mathrm{~h}$ at $120^{\circ} \mathrm{C}$ for functionalization, the dried capillaries were purged with ethanol and pure water sequentially $(30 \mathrm{~min})$ to remove unreacted reagent before equilibration with buffer solution. The columns were then ready for use. When the columns were not in use, they were stored only in pure water. 

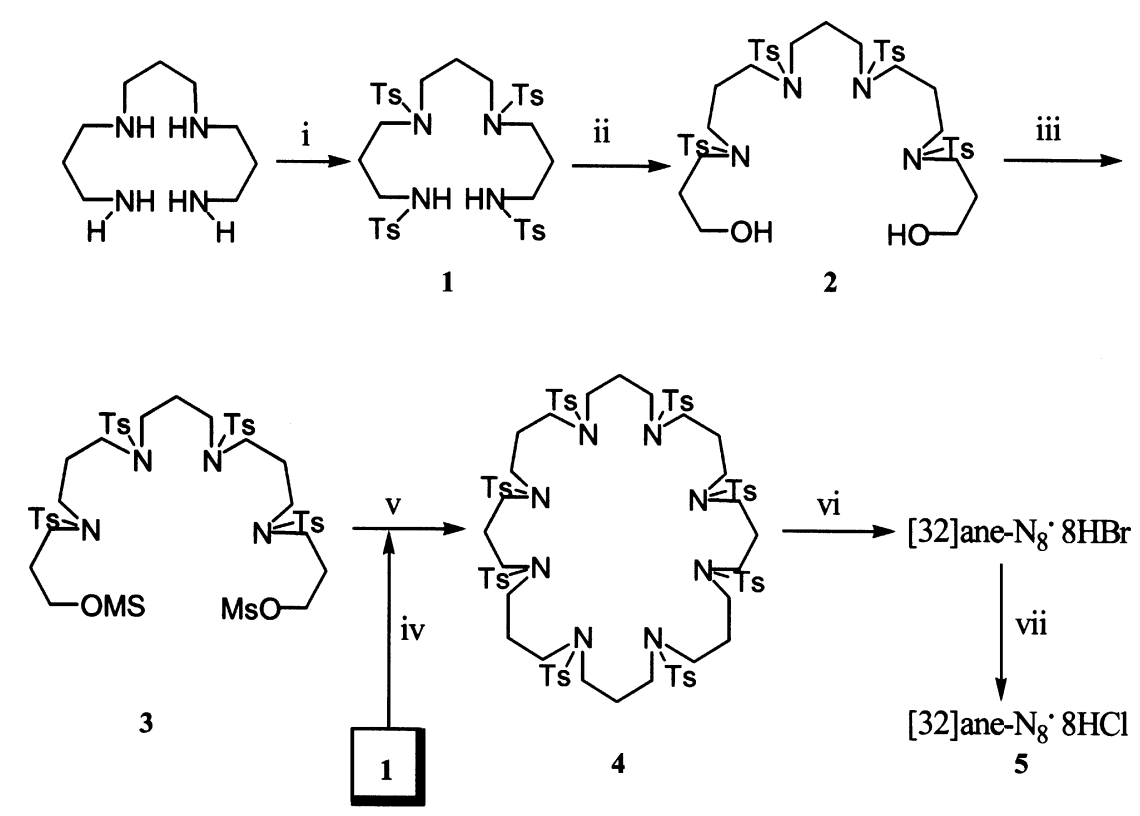

Reagents: (i) $\mathrm{TsCl} / \mathrm{K}_{2} \mathrm{CO}_{3} / \mathrm{H}_{2} \mathrm{O}$; (ii) 3-chloro-1-propanol $/ \mathrm{K}_{2} \mathrm{CO}_{3} / \mathrm{DMF}$; (iii) $\mathrm{MsCl} / \mathrm{Et}_{3} \mathrm{~N} / \mathrm{dry}_{\mathrm{CH}} \mathrm{Cl}_{2} /-18^{\circ} \mathrm{C}$; (iv) $\mathrm{NaH} / \mathrm{DMF} / \mathrm{stir}$ at $\mathrm{rt}$; (v) $\mathrm{DMF} / 110^{\circ} \mathrm{C}$; (vi) $33 \% \mathrm{HBr}-\mathrm{AcOH} / \mathrm{PhOH} / 80{ }^{\circ} \mathrm{C}$; (vii) Dowex $1 \mathrm{X} 8 / \mathrm{Cl}^{-}$.

Fig. 1. Synthetic procedures of a 32-membered octaazamacrocyclic molecule, [32]ane- $\mathrm{N}_{8} \cdot 8 \mathrm{HCl}$.

\subsection{Precolumn derivatization with p-aminobenzoic acid}

Following the procedures described by Fischer et al. [37] $p$ aminobenzoic acid $(0.35 \mathrm{M})$ was prepared in a DMSO/acetic acid solution $(7: 3, \mathrm{v} / \mathrm{v})$. To the mixture of $p$-aminobenzoic acid $(0.35 \mathrm{M}, 0.5 \mathrm{~mL})$ and analyte solution $(5 \mathrm{mg} / \mathrm{mL}, 0.2 \mathrm{~mL})$, sodium cyanoborohydride $(10 \mathrm{mg})$ was then added. The derivatization was carried out at $60^{\circ} \mathrm{C}$ for $15 \mathrm{~min}$. The resultant product was diluted 100 -fold prior to use.

\subsection{Capillary electrochromatographic conditions}

Before analysis, the column of the macrocyclic polyamine bonded phase was preconditioned with the running buffer. They were rinsed with pure water and buffer between runs at 1 or $2 \mathrm{~min}$ intervals. The samples were injected by hydrostatic mode. EOF was measured with benzyl alcohol as a neutral marker. The fluorometric detection was carried out by on-column measurement with excitation wavelength of $313 \mathrm{~nm}$ and emission wavelength of $358 \mathrm{~nm}$.

\section{Results and discussion}

The procedures for the preparation of the bonded phase are outlined in Fig. 2. The reaction for the amination with epoxide is moisture sensitive. Therefore, it has been carried out in nonaqueous solvent. But when it is applied to the CEC separation, the $\mathrm{Si}-\mathrm{OCH}_{3}$ groups in the bonded phase give $\mathrm{Si}-\mathrm{OH}$ in aqueous environment. For characterization of the prepared column, both diffuse reflectance infrared Fourier transform spectroscopy and EOF measurement as a function of $\mathrm{pH}$ are amenable to the analysis [38]. Here, the direction and quantity of the EOF were measured as in Fig. 3. By comparison with that of [28]ane- $\mathrm{N}_{6} \mathrm{O}_{2}$ [28], the reversal of EOF was indicated only below $\mathrm{pH}$ 7.0. It can be concluded that the bulky structure faces difficulty in binding with fused silica, as the ring size of [32] ane- $\mathrm{N}_{8}$ is greater than that of [28] ane- $\mathrm{N}_{6} \mathrm{O}_{2}$. Therefore, the silanol groups surpassed the positively charged ammonium groups of [32]ane- $\mathrm{N}_{8}$ on the bonded phase when the $\mathrm{pH}$ was above 7.0.

The carbohydrates: two pentoses, three hexoses, and three disaccharides were considered for analytes. D-glucose, Dmannose and D-galactose are epimers. Maltose consists of two residues of $\alpha$-D-glucose in an $\alpha(1 \rightarrow 4)$ linkage. Cellobiose consists of two residues of $\beta$-D-glucose in a $\beta(1 \rightarrow 4)$ linkage. Melibiose is a disaccharide consisting of one galactose and one glucose moiety in an $\alpha(1 \rightarrow 6)$ glycosidic linkage. In contrast to most other reagents used for reductive amination, $p$-aminobenzoic acid allows efficient derivatization of carbohydrates in a more conductive condition [37]. Besides, the
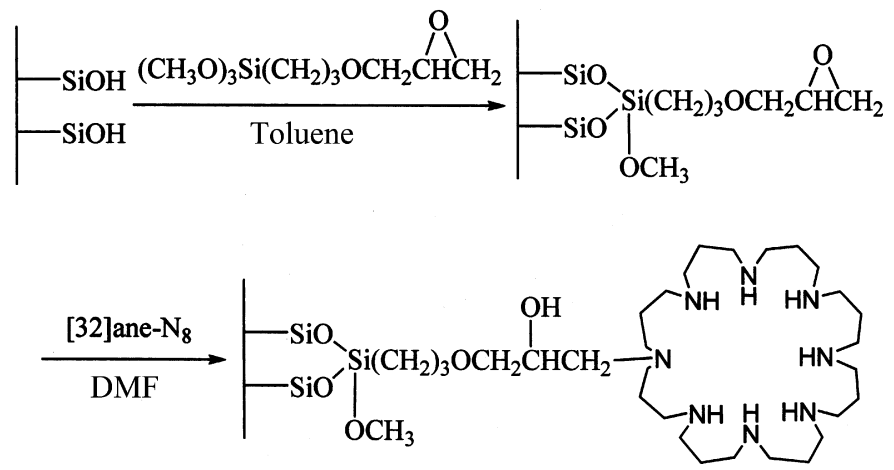

Fig. 2. Schematic representation of the procedures for the column preparation. 


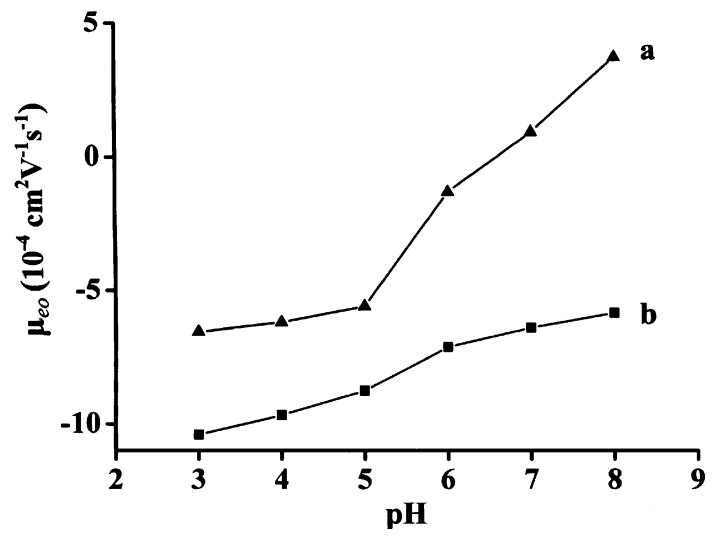

Fig. 3. Effect of $\mathrm{pH}$ on electroosmotic flow mobility in various capillary columns. Column: bonded phase fused silica capillary, $100 \mathrm{~cm}(60 \mathrm{~cm}) \times 75 \mu \mathrm{m}$ i.d.; injection mode: electrokinetic ( $5 \mathrm{kV}, 10 \mathrm{~s})$; EOF marker: benzyl alcohol; mobile phase: phosphate buffer $(30 \mathrm{mM})$; applied voltage: $15 \mathrm{kV}$; UV detection at $214 \mathrm{~nm}$. (a) (ム) [32]ane- $\mathrm{N}_{8}$, (b) (ロ) [28]ane- $\mathrm{N}_{6} \mathrm{O}_{2}$. formation of a charged carboxylate (Fig. 4) was favored in the CEC complexation with the prepared bonded phase.

Discrimination of polar structures of organic ions by the macrocyclic polyamine bonded phase can be achieved on the basis of electrostatic interaction and hydrogen bonding with the polar moieties of guests besides the macrocyclic effect. Based on the above consideration, several parameters were examined to optimize the separation conditions.

\subsection{Effect of $\mathrm{pH}$ on the separation}

Borates are very reactive species that can be used as separation buffers for the capillary electrophoresis or micellar electrokinetic chromatographic analysis of various polyols [39]. Thus, in a preliminary study, $150 \mathrm{mM}$ borate buffer was used as the mobile phase. At $\mathrm{pH} \mathrm{7.0,} \mathrm{it} \mathrm{was} \mathrm{found} \mathrm{that} \mathrm{all} \mathrm{ana-}$ lytes were eluted simultaneously. The separation was improved significantly with the increase of $\mathrm{pH}$. At $\mathrm{pH} 9.0$, most of the analytes, except D-mannose and D-glucose, could be partially or completely resolved (Fig. 5).

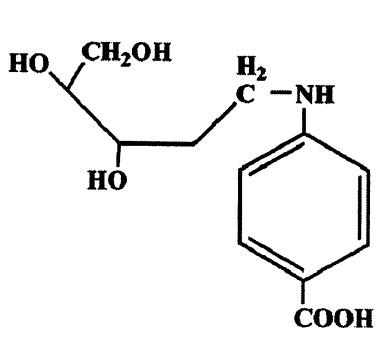

(A)

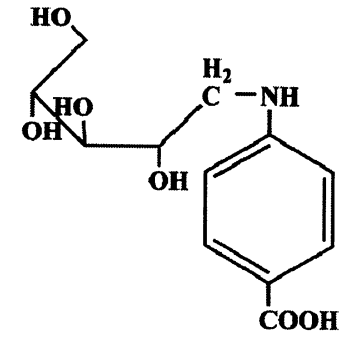

(B)<smiles>O=C(O)c1ccc(NCC(O)C(O)C(O)C(O)CO)cc1</smiles>

(C)<smiles>O=C(O)c1ccc(NCC(O)C(O)C(O)C(O)CO)cc1</smiles>

(D)<smiles>O=C(O)c1ccc(NCC(O)C(O)N(O)C(O)CO)cc1</smiles>

(E)<smiles>O=C(O)c1ccc(NCC(O)C(O)C(O)C2OC(CO)C(O)C(O)C2O)cc1</smiles>

(F)
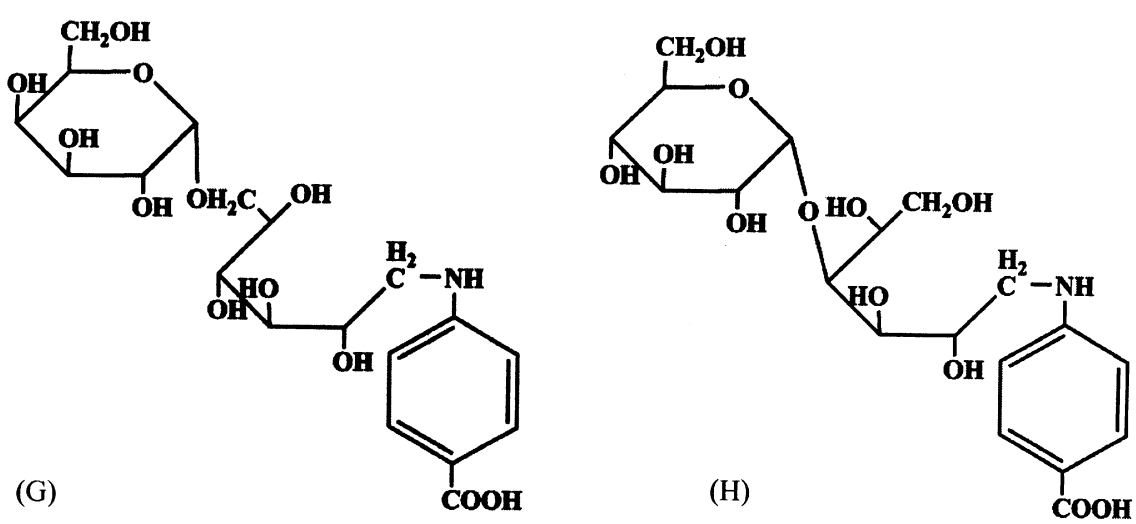

Fig. 4. The structure of the derivatized carbohydrates. (A) 2-Deoxy-D-ribose, (B) D-xylose, (C) D-galactose, (D) D-mannose, (E) D-glucose, (F) cellobiose, (G) melibiose, $(\mathrm{H})$ maltose. 

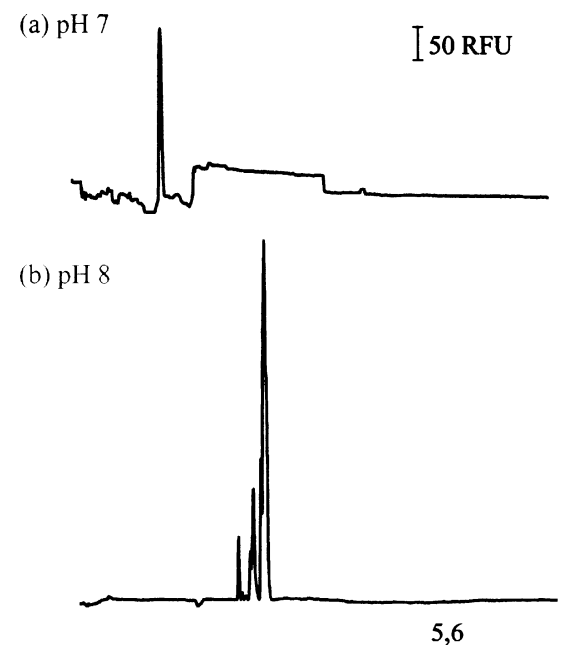

(c) $\mathrm{pH} 9$

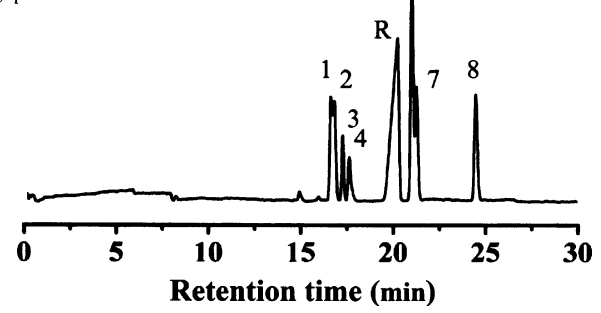

Fig. 5. Effect of borate buffer $\mathrm{pH}$ on separation of derivatized mono- and disaccharides. Column: [32] ane- $\mathrm{N}_{8}$ bonded phase fused silica capillary; $100 \mathrm{~cm}$ $(60 \mathrm{~cm}) \times 75 \mu \mathrm{m}$ i.d.; sample injection: hydrostatic $(20 \mathrm{~cm}, 20 \mathrm{~s})$; applied voltage: $20 \mathrm{kV}$; detection: $\lambda_{\mathrm{ex}}=313 \mathrm{~nm}$ and $\lambda_{\mathrm{em}}=358 \mathrm{~nm}$. Mobile phase: borate buffer $150 \mathrm{mM}$ at (a) $\mathrm{pH} 7.0$, (b) $\mathrm{pH}$ 8.0, (c) $\mathrm{pH}$ 9.0. Peak identification: (1) 2-deoxy-D-ribose, (2) cellobiose, (3) melibiose, (4) maltose, (5) D-mannose, (6) D-glucose, (7) D-xylose, (8) D-galactose, (R) reagent.

\subsection{Effect of buffer concentration}

To investigate the contribution of borate to the separation, the effect of borate buffer concentration was investigated (Fig. 6a). Only four peaks were observed at $30 \mathrm{mM}$. Increasing the borate concentration to $60 \mathrm{mM}$ caused an increase of both retention time and resolution. Both boric acid and borate are known to form complex with diol groups of the proper geometry in cyclic and noncyclic polyhydroxy compounds [39]. It gives bidentate or terdentate complex. cis 1,2-Diols are preferred in complexation to trans 1,2-diols and a higher stability was found when the hydroxyls of the 1,2-diol are in the threo position. In this work, most of the elution order was in agreement with the prediction. For the disaccharide, $\beta$-linkage (cellobiose) was eluted earlier than $\alpha$-linkage (melibiose) due to the steric hindrance. 1,3-Diol complex in D-glucose might have less hindrance than cis 1,2-diol complex in D-mannose for the $p$-aminobenzoate insersion into the cavity of [32]ane- $\mathrm{N}_{8}$. So, a greater retention for $\mathrm{D}$-glucose was observed.

No siginificant difference for the retention times was observed over the concentration range of $70-90 \mathrm{mM}$, except D-glucose eluted after reagent. When the concentration was increased to $110 \mathrm{mM}$, not only did the eluting rate increase remarkably for the early eluted saccharides, but complete resolution of D-xylose and D-galactose was achieved. D-Galactose has more cis 1,2-diols than D-xylose. The complexation with borate
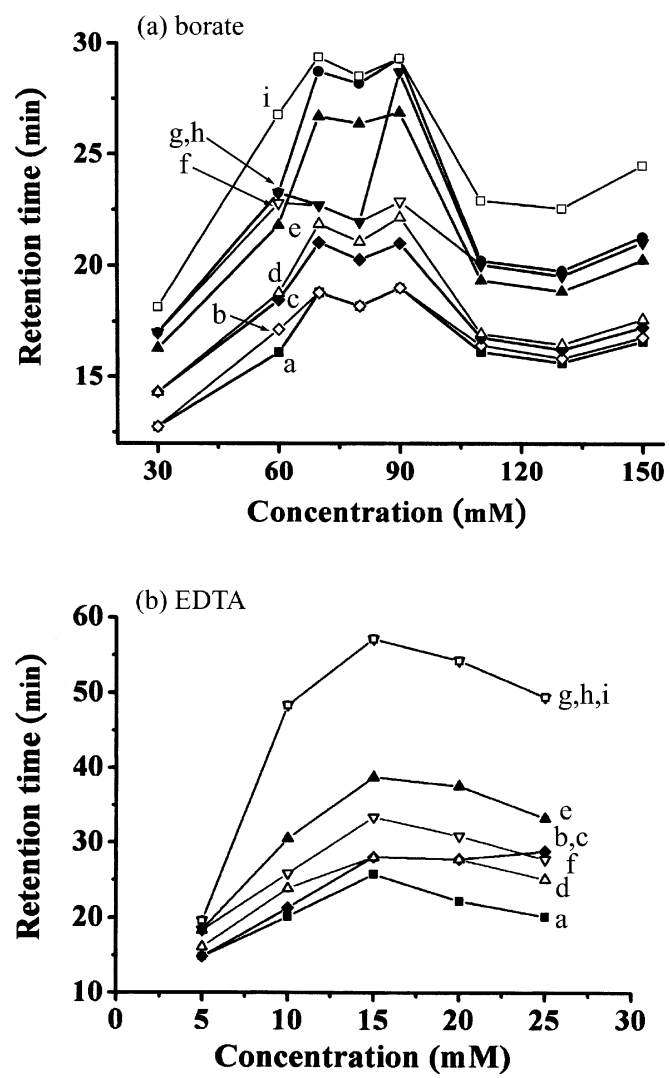

Fig. 6. Effect of buffer concentration on the retention time of derivatized carbohydrates. Column: [32] ane- $\mathrm{N}_{8}$ bonded phase fused silica capillary; $100 \mathrm{~cm}$ $(60 \mathrm{~cm}) \times 75 \mu \mathrm{m}$ i.d.; sample injection: hydrostatic $(20 \mathrm{~cm}, 20 \mathrm{~s})$; applied voltage: $20 \mathrm{kV}$; detection: $\lambda_{\mathrm{ex}}=313 \mathrm{~nm}$ and $\lambda_{\mathrm{em}}=358 \mathrm{~nm}$; mobile phase $(\mathrm{pH} 9.0)$ : (a) borate buffer, (b) EDTA buffer. (a) (ם) 2-Deoxy-D-ribose, (b) ( $\diamond$ ) cellobiose, (c) $(\checkmark)$ melibiose, (d) $(\triangle)$ maltose, (e) $(\mathbf{\Lambda})$ reagent, (f) $(\nabla)$ D-mannose, (g) ( $\mathbf{\nabla})$ D-glucose, (h) (๑) D-xylose, (i) ( $\square$ ) D-galactose.

buffer seems more effective at this concentration. This results in distinct behavior for the interaction with the bonded phase. As the concentration was further increased up to $150 \mathrm{mM}$, the effect of ionic strength on EOF seems to surpass the mentioned electrostatic reaction. So, a slower elution for all analytes was seen again.

\subsection{Effect of other buffer composition on the separation}

For increasing the separation efficiency, several competitive ligands for the anion coordination with the bonded phase were chosen for further experiments.

\subsubsection{Borate buffer/methanol}

In the borate buffer $(130 \mathrm{mM}, \mathrm{pH} 9.0)$, the addition of methanol (ranging from 5\% to 10\%) improved resolution for the compounds eluting prior to the derivatizing agent (Table 1). But it was not for those eluted after the derivatizing agent. Methanol content greater than $10 \%$ led to a serious loss in resolution.

\subsubsection{Tris buffer}

Tris buffer at different concentration was studied. At $\mathrm{pH}$ 9.0, all conditions revealed only one peak $(14.26 \mathrm{~min}$ at $10 \mathrm{mM}$; 
Table 1

Effect of methanol content on retention time and resolution in the CEC separation of derivatized carbohydrates ${ }^{\mathrm{a}}$

\begin{tabular}{|c|c|c|c|c|c|c|}
\hline \multirow[t]{2}{*}{ Saccharides } & \multicolumn{2}{|l|}{$0 \%$} & \multicolumn{2}{|l|}{$5 \%$} & \multicolumn{2}{|l|}{$10 \%$} \\
\hline & $t_{\mathrm{R}}(\min )$ & $R_{\mathrm{S}}^{\mathrm{b}}$ & $t_{\mathrm{R}}(\min )$ & $R_{\mathrm{s}}$ & $t_{\mathrm{R}}(\min )$ & $R_{\mathrm{S}}$ \\
\hline 2-Deoxy-D-ribose & 15.64 & - & 16.68 & - & 23.91 & - \\
\hline Cellobiose & 15.84 & 0.68 & 16.92 & 0.68 & 23.91 & - \\
\hline Melibiose & 16.23 & 1.46 & 17.36 & 1.49 & 24.59 & 1.48 \\
\hline Maltose & 16.46 & 0.82 & 18.00 & 1.96 & 26.26 & 3.50 \\
\hline Reagent & 18.85 & 3.81 & 20.80 & 4.09 & 30.56 & 5.19 \\
\hline D-Mannose & 19.55 & 2.12 & 21.56 & 1.51 & 31.23 & 0.91 \\
\hline D-Glucose & 19.55 & - & 21.56 & - & 31.23 & - \\
\hline D-Xylose & 19.77 & 0.67 & 21.73 & 0.27 & 31.52 & 0.81 \\
\hline D-Galactose & 22.56 & 9.42 & 25.20 & 10.33 & 31.86 & 0.92 \\
\hline
\end{tabular}

a Column: [32] ane- $\mathrm{N}_{8}$ bonded phase; $100 \mathrm{~cm}(60 \mathrm{~cm}) \times 75 \mu \mathrm{m}$ i.d.; sample injection: hydrostatic $(20 \mathrm{~cm}, 20 \mathrm{~s})$; mobile phase: borate buffer $(130 \mathrm{mM}, \mathrm{pH}$ 9.0); applied voltage: $20 \mathrm{kV}$; detection: $\lambda_{\mathrm{ex}}=313 \mathrm{~nm}, \lambda_{\mathrm{em}}=358 \mathrm{~nm}$.

b Resolution $\left(R_{\mathrm{S}}\right)=2\left(t_{\mathrm{R} 2}-t_{\mathrm{R} 1}\right) /\left(w_{2}+w_{1}\right)$, where $t_{\mathrm{R}}$ is retention time, $w$ is peak width.

$18.98 \mathrm{~min}$ at $20 \mathrm{mM} ; 32.26 \mathrm{~min}$ at $30 \mathrm{mM}$ ). Increasing the ionic strength resulted in longer retention time but did not affect the resolution. The results indicated that the competition is not remarkable due to the weak interaction of the neutral amino group in the Tris molecule.

\subsubsection{EDTA buffer}

EDTA $\left(\mathrm{H}_{4} \mathrm{Y}\right)$ has four carboxylate and two amino groups. It is a good ligand for the macrocyclic polyamine [40]. Thus, the influence of EDTA on the separation was also investigated (Fig. 6b). Longer retention time was indicated as the concentration of EDTA was increased from $5 \mathrm{mM}$ to $15 \mathrm{mM}$. This was due to zeta potential and EOF decrease as ionic strength increased. But as the EDTA concentration was increased beyond $20 \mathrm{mM}$, less retention was shown. Here, sample was applied at the anode and detected at the cathode. The main species of EDTA at $\mathrm{pH}$ 9.0 is $\mathrm{HY}^{3-}$. Protonation constants of [32] ane- $\mathrm{N}_{8}$, which are $6.50,6.85,7.55,8.20,9.20,9.70,10.55$ and 10.65 , have been reported by Dietrich et al. [41]. The calculated effective charges are $8.000(\mathrm{pH} 3.0), 7.997(\mathrm{pH} 4.0), 7.968(\mathrm{pH} 5.0) 7.699(\mathrm{pH}$ 6.0), $6.376(\mathrm{pH} 7.0), 4.851(\mathrm{pH} 8.0), 3.624(\mathrm{pH} 9.0)$ and 2.133 ( $\mathrm{pH}$ 10.0). In our cases, one amino group of the polyamine is covalently bonded to the fused-silica (Fig. 2). Seven free amino groups remain in this heterogeneous system. We can conclude that even at $\mathrm{pH}$ 9.0, more than two nitrogen atoms can be protonated. In other words, increase in the EDTA concentration would reduce the affinity of the analyte with the bonded phase. This made the elution of analyte faster.

By careful consideration of the retention times shown in Figs. 6a,b and 8, the longest retention times were obtained with the EDTA buffer. This can explain that the ionic size of EDTA is not matching the cavity of the bonded macrocyclic polyamine. So, the displacement reaction is not as easy as that for the other buffer.

\subsubsection{Phosphate buffer}

As shown in Fig. 5, borate buffer of $\mathrm{pH} 9.0$ provided the best separation. In order to see the performance of other buffers

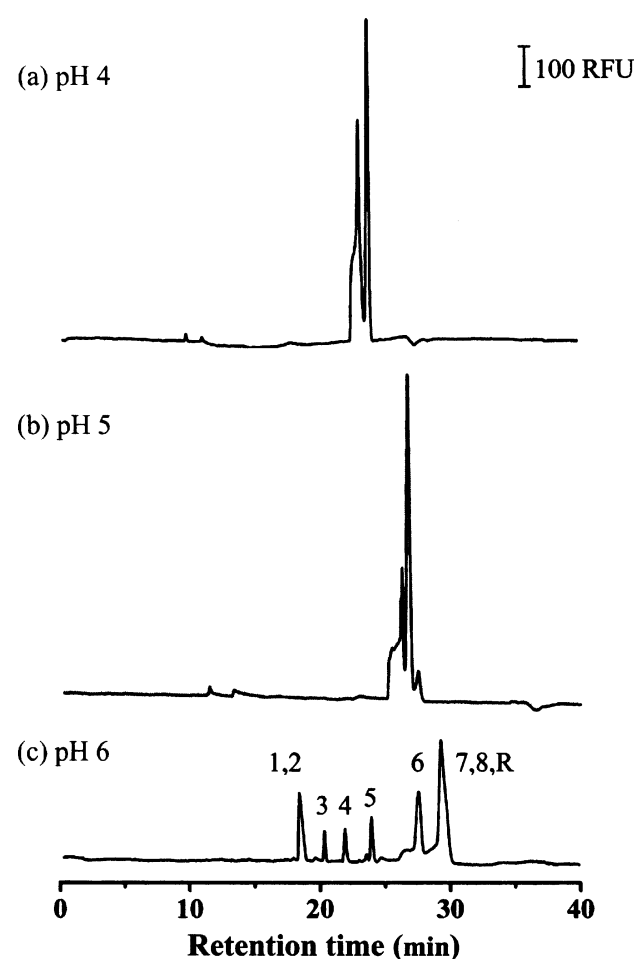

Fig. 7. Separation of derivatized carbohydrates on the bonded phase with phosphate buffer at different $\mathrm{pH}$. Column: [32]ane- $\mathrm{N}_{8}$ bonded phase: $100 \mathrm{~cm}$ $(60 \mathrm{~cm}) \times 75 \mu \mathrm{m}$ i.d.; sample injection: hydrostatic $(20 \mathrm{~cm}, 20 \mathrm{~s})$; applied voltage: $-20 \mathrm{kV}$; detection: $\lambda_{\mathrm{ex}}=313 \mathrm{~nm}, \lambda_{\mathrm{em}}=358 \mathrm{~nm}$; mobile phase: phosphate buffer $(30 \mathrm{mM})$ at (a) $\mathrm{pH} 4.0$, (b) $\mathrm{pH} 5.0$, (c) $\mathrm{pH}$ 6.0. Peak identification: (1) 2-deoxy-D-ribose, (2) D-xylose, (3) D-mannose, (4) D-glucose, (5) D-galactose, (6) cellobiose, (7) melibiose, (8) maltose, (R) reagent.

at similar condition, Tris and EDTA buffers were investigated. However, resolution between peaks remained far from being acceptable. To elucidate the separation mechanism whether it was stemmed from the molecular recognition of macrocyclic polyamine or borate complex formation, phosphate buffer of $\mathrm{pH} 4.0-6.0$ was selected for the experiment. The condition is expected to be most favorable for the anion coordination where the bonded phase is fully protonated and the carbohydrate derivatives carry the negative charge.

But at $\mathrm{pH} 4.0$ and 5.0, the mixture of two pentoses, three hexoses and three disaccharides was eluted only as two unsymmetrical peaks. At pH 6.0, six peaks were demonstrated (Fig. 7). The elution rate decreased as the molecular size increased. 2Deoxy-D-ribose and D-xylose were coeluted. Pentose has less $\mathrm{OH}$ groups, and certainly has less hydrogen bonding interaction. So they were eluted first. Among the three epimers, the elution sequence is mannose $>$ glucose $>$ galactose. For the disaccharides, the elution order is cellobiose $>$ melibiose $=$ maltose, where $\beta$-linkage is eluted earlier than the $\alpha$-linkage. $\mathrm{pH} 6.0$ seems more advantageous for the anion recognition between derivatized analyte and the bonded phase. The phosphate concentration was further varied over the range from $10 \mathrm{mM}$ to $50 \mathrm{mM}$. Only $30 \mathrm{mM}$ and $40 \mathrm{mM}$ revealed six peaks for the eight compounds injected (Fig. 8). At higher concentration, competition with the analyte toward the bonded phase was seen apparently. 


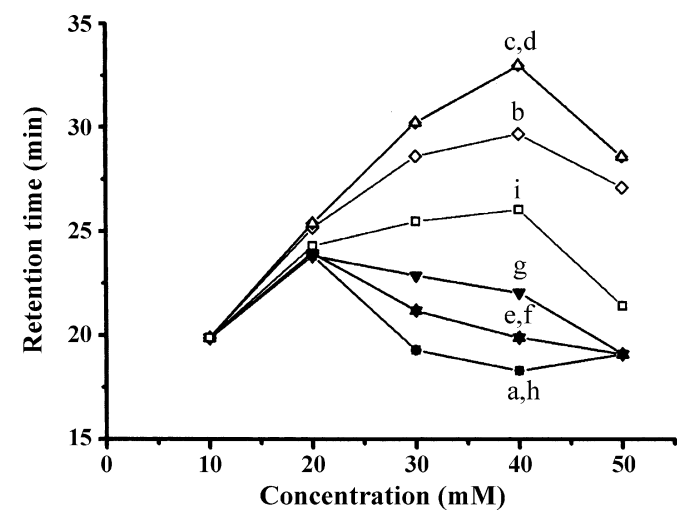

Fig. 8. Separation of derivatized carbohydrates on the bonded phase with various concentration of phosphate buffer. Column: [32] ane- $\mathrm{N}_{8}$ bonded phase: $100 \mathrm{~cm}$ $(60 \mathrm{~cm}) \times 75 \mu \mathrm{m}$ i.d.; sample injection: hydrostatic $(20 \mathrm{~cm}, 20 \mathrm{~s})$; applied voltage: $-20 \mathrm{kV}$; detection: $\lambda_{\mathrm{ex}}=313 \mathrm{~nm}, \lambda_{\mathrm{em}}=358 \mathrm{~nm}$; mobile phase: phosphate buffer at pH 6.0. (a) (ם) 2-Deoxy-D-ribose, (b) ( $\diamond)$ cellobiose, (c) $(\downarrow)$ melibiose, (d) $(\triangle)$ maltose, (e) $(\mathbf{\Delta})$ reagent, (f) $(\nabla)$ D-mannose, (g) ( $\mathbf{\nabla})$ D-glucose, (h) ( D-xylose, (i) ( $\square$ ) D-galactose.

\subsection{Separation with a concentration gradient buffer system}

Among the mobile phases chosen, borate buffer gave the best performance for the separation. In order to hasten and improve the separation, concentration gradients of 60-70, 60-90, 30-90,
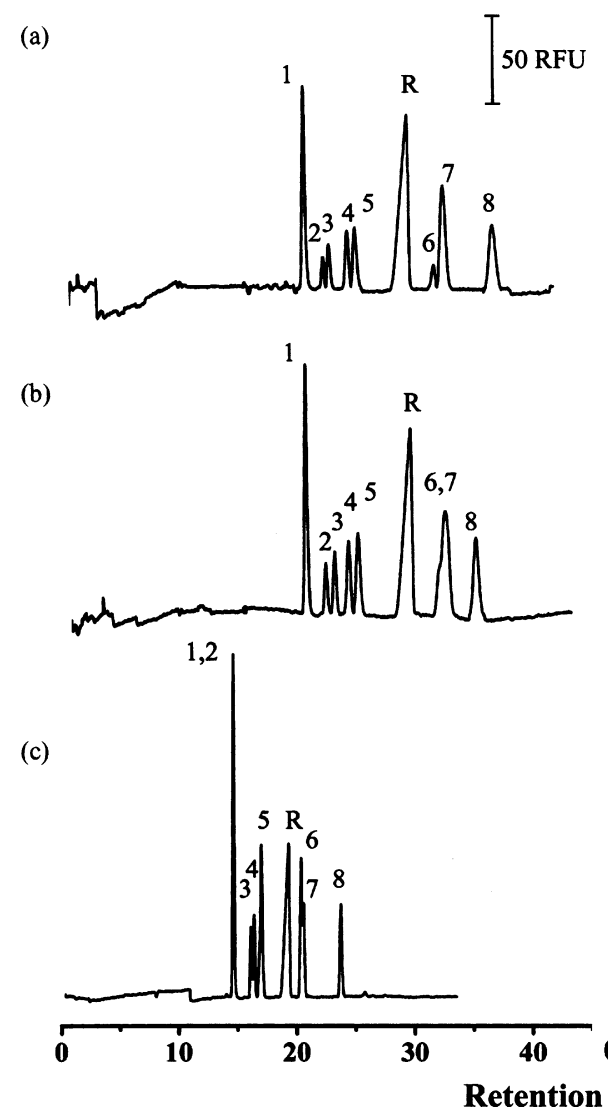

Retention time (min)

Fig. 9. Electrochromatograms of derivatized carbohydrates separated with concentration gradient of borate buffer. Column: (a-e) [32]ane- $\mathrm{N}_{8}$ bonded phase fused silica capillary, (f) bare fused-silica capillary; $100 \mathrm{~cm}(60 \mathrm{~cm}) \times 75 \mu \mathrm{m}$ i.d.; sample injection: hydrostatic $(20 \mathrm{~cm}, 20 \mathrm{~s})$; applied voltage: $20 \mathrm{kV}$; detection: $\lambda_{\mathrm{ex}}=313 \mathrm{~nm}$ and $\lambda_{\mathrm{em}}=358 \mathrm{~nm}$; borate buffer (pH 9.0) with gradient of (a) and (f) 60-70 mM, (b) 60-90 mM, (c) 30-90 mM, (d) 90-30 mM, (e) 70-60 mM. Peak identification: (1) 2-deoxy-D-ribose, (2) cellobiose, (3) melibiose, (4) maltose, (5) D-mannose, (6) D-glucose, (7) D-xylose, (8) D-galactose, (R) reagent.
90-30 and 70-60 $\mathrm{mM}$ were investigated. The former concentration was put into the inlet side while the latter buffer was placed into the outlet end. A concentration gradient of $60-70 \mathrm{mM}$ gave the best separation conditions (Fig. 9a). All analytes and the surplus reagent were completely resolved. Increase in the gradient range did not improve the resolution, but only reduced the retention time. Attempts to interchange the gradient mode from higher to lower concentration resolved only two peaks.

\subsection{Comparison the retention behavior of the bonded phase with that of the bare fused silica}

The optimum condition for the separation of carbohydrates was achieved with borate buffer ( $\mathrm{pH}$ 9.0) in a mode of concentration gradient of $60-70 \mathrm{mM}$ with the bonded phase (Fig. 9a). In order to clarify the role of the bonded phase, carbohydrates were separated with the bare fused-silica under the identical conditions. By comparison with the results shown in Fig. 9f, lower peak height and longer elution time indicate a greater interaction force between the bonded phase and the analytes. Besides, different elution order and better resolution, especially for the separation of reagent and D-mannose as well as D-glucose give another evidence for the superior molecular recognition of the bonded phase.

(d)

(e)

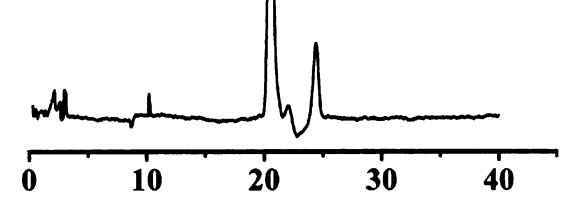

(f)

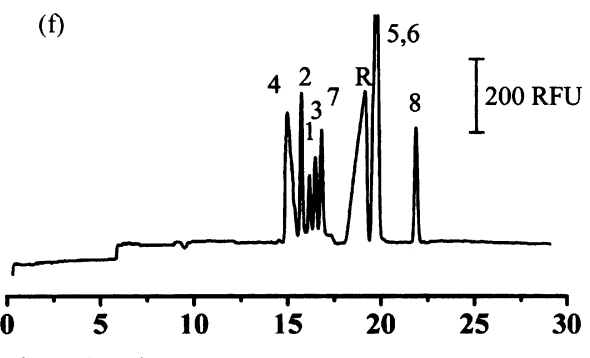


Table 2

Separation efficiency of derivatized carbohydrates

\begin{tabular}{llll}
\hline Saccharides & $t_{\mathrm{R}}(\min )^{\mathrm{a}}$ & $\operatorname{RSD}(\%)^{\mathrm{b}}$ & $N(\text { plates } / \mathrm{m})^{\mathrm{c}}$ \\
\hline 2-Deoxy-D-ribose & 20.21 & 0.75 & 32000 \\
Cellobiose & 21.88 & 0.38 & 46000 \\
Melibiose & 22.32 & 0.66 & 34000 \\
Maltose & 24.10 & 0.33 & 30000 \\
D-Mannose & 25.13 & 1.31 & 27000 \\
D-Glucose & 31.29 & 0.38 & 54000 \\
D-Xylose & 33.11 & 3.77 & 21000 \\
D-Galactose & 37.75 & 3.58 & 20000 \\
\hline
\end{tabular}

a Six consecutive injections. Conditions as mentioned in Fig. 9a.

b Relative standard deviation.

c Number of theoretical plate $(N)=5.54\left(t_{\mathrm{R}} / w_{1 / 2}\right)^{2}$, where $w_{1 / 2}$ is the peak width at half height.

\subsection{Stability of the column}

For assay the column preparation procedure, column-tocolumn repeatability was determined by testing six columns. Under the condition of phosphate buffer $(30 \mathrm{mM}, \mathrm{pH} 4.0)$ and applied voltage of $-20 \mathrm{kV}$, the relative standard deviation (RSD) of the EOF was less than $3.20 \%$. While with borate buffer $(\mathrm{pH}$ 9.0 , concentration gradient of $60-70 \mathrm{mM}$ ), an applied voltage of $20 \mathrm{kV}$ and fluorometric detection at $358 \mathrm{~nm}$, the separation efficiency for the analytes was expressed as an average of 33000 theoretical plates/m (Table 2). With six consecutive injections, the RSD of the retention time was within $0.75 \%$, except those of D-mannose (1.31\%), D-xylose (3.77\%) and D-galactose (3.58\%). These results indicated that the bonded phase and the gradient formed inside the column were quite stable.

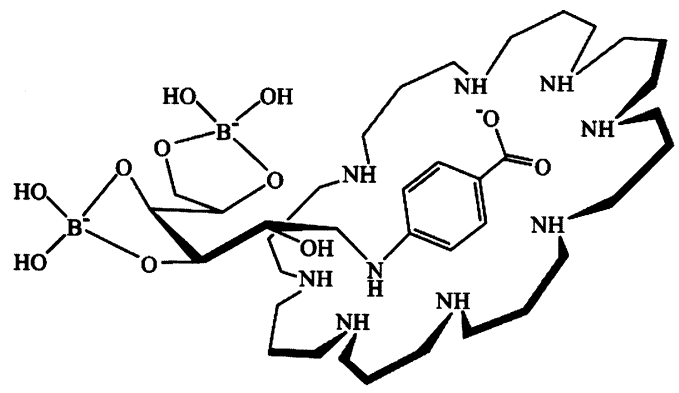

(A) Monosaccharide

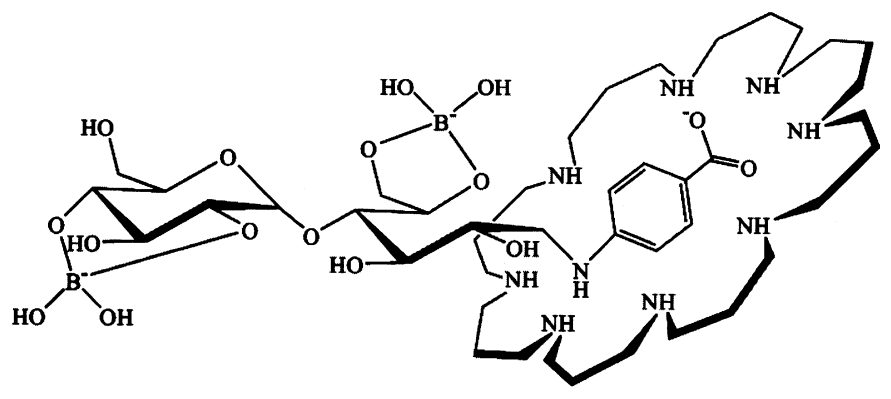

(B) Disaccharide

Fig. 10. Suggested structure for the anion coordination of the carbohydrate derivatives with the bonded phase in the presence of borate buffer.

\section{Conclusion}

A novel macrocyclic polyamine ([32] ane- $\mathrm{N}_{8}$ ) bonded phase was introduced for the separation of carbohydrates. The derivatization of carbohydrates with $p$-aminobenzoic acid facilitates the CEC separation and fluorometric detection. Although inclusion into well-defined hydrophobic cavities of hosts affords a general principle for the structural discrimination in aqueous systems, different mobile phases (borate, borate/methanol, Tris, EDTA and phosphate) exhibit different retention behavior. Depending on the polarity of the applied potential and the direction of EOF, either bonded phase with or without borate buffer can be conductive to the separation. Borate buffer gives the best separation of the derivatized carbohydrates with the bonded phase (Fig. 9a).

As the mechanism shown in Fig. 10 suggests, the anion coordination seems to be mainly contributed from the insertion of the carboxylate and amino group of the derivatized product into the cavity, along with the electrostatic interaction/anion exchange, hydrogen bonding and hydrophobic interaction of the flexible borate complex with the bonded phase. The column used a concentration gradient which greatly improved the resolution. The method presents a valuable way to separate the epimers, and disaccharides with different glycosidic linkage as well as the remaining reagent, thus excluding interference between the reagent and its derivatives. The bonded phase might offer an easy way to determine the saccharides in a complex matrix samples. That is to say the macrocylic polyamine has great potential for proteomics applications that focus on the identification and quantification of glycoproteins.

\section{Acknowledgement}

The authors thank the National Science Council of Taiwan for financial support (Grant No. NSC 94-2113-M-002-015).

\section{References}

[1] P.A. Gale, Coord. Chem. Rev. 240 (2003) 1.

[2] P.D. Beer, P.A. Gale, Angew. Chem. Int. Ed. 40 (2001) 486.

[3] C.A. Ilioudis, J.W. Steed, J. Supramol. Chem. 1 (2001) 165.

[4] J.L. Sessler, P.A. Gale, W.S. Cho, Anion Receptor Chemistry, RSC Publishing, UK, 2006.

[5] A. Bianchi, K. Bowman-James, E. Garcia-España (Eds.), Supramolecular Chemistry of Anions, Wiley-VCH, New York, 1997.

[6] S. Naher, K. Hiratani, S. Ito, J. Incl. Phenom. Macrocycl. Chem. 55 (2006) 151.

[7] P. Cudic, A. Addo-Mensah, Abs. of the 230th ACS National Meeting, Washington, DC, USA, August 28-September 1, 2005.

[8] K. Kobayashi, F. Ikeuchi, S. Inaba, Y. Aoyama, J. Am. Chem. Soc. 114 (1992) 1105

[9] Y. Aoyama, Y. Tanaka, S. Sugahara, J. Am. Chem. Soc. 111 (1989) 5397.

[10] J. Kraly, M.A. Fazal, R.M. Schoenherr, R. Bonn, M.M. Harwood, E. Turner, M. Jones, N.J. Dovichi, Anal. Chem. 78 (2006) 4097.

[11] K.D. Altria (Ed.), Capillary Electrophoresis Guidebook: Principles, Operations and Applications, Human Press, Totowa, New Jersey, 1996.

[12] S. Suzuki, S. Honda, Electrophoresis 24 (2003) 3577.

[13] M. Guček, B. Pihlar, Acta Chim. Slov. 47 (2000) 165.

[14] D.T. Nguyen, H. Lerch, A. Zemann, G. Bonn, Chromatographia 46 (1997) 113.

[15] C.D. Garcia, C.S. Henry, Electrophoresis 17 (2005) 223.

[16] A. Rainelli, P.C. Hauser, Anal. Bioanal. Chem. 382 (2005) 789. 
[17] G. Huang, Y. Lv, S. Zhang, C. Yang, X. Zhang, Anal. Chem. 77 (2005) 7356.

[18] G. Joucla, T. Brando, M. Remaud-Simeon, P. Monsan, G. Puzo, Electrophoresis 25 (2004) 861.

[19] J. Cabálková, J. Žídková, L. Přibyla, J. Chmelík, Electrophoresis 25 (2004) 487.

[20] K. Harada, E. Fukusaki, A. Kobayashi, J. Biosci. Bioeng. 101 (2006) 403.

[21] H. Suzuki, O. Mueller, A. Guttman, B.L. Karger, Anal. Chem. 69 (1997) 4554.

[22] D. Allen, Z. El Rassi, J. Chromatogr. A 1029 (2004) 239.

[23] S. Kamoda, Y. Nakanishi, M. Kinoshita, R. Ishikawa, K. Kakehi, J. Chromatogr. A 1106 (2006) 67.

[24] A.H. Que, M.V. Novotny, Anal. Chem. 74 (2002) 5184.

[25] F.M. Okanda, Z. El Rassi, Electrophoresis 27 (2006) 1020.

[26] C. Yang, Z. El Rassi, Electrophoresis 19 (1998) 2061.

[27] J.C. Hsu, W.H. Chen, C.Y. Liu, Analyst 122 (1997) 1393.

[28] C.Y. Liu, W.H. Chen, J. Chromatogr. A 815 (1998) 251.

[29] W.H. Chen, C.Y. Liu, J. Chromatogr. A 848 (1999) 401.
[30] W.H. Chen, S.Y. Lin, C.Y. Liu, Anal. Chim. Acta 410 (2000) 25.

[31] S.Y. Lin, W.H. Chen, C.Y. Liu, Electrophoresis 23 (2002) 1230.

[32] S.Y. Lin, C.Y. Liu, Electrophoresis 24 (2003) 2973.

[33] W.H. Chen, C.C. Lin, T.S. Chen, T.K. Misra, C.Y. Liu, Electrophoresis 24 (2003) 970.

[34] S.Y. Lin, C.Y. Liu, J. Incl. Phenom. Macrocycl. Chem. 48 (2004) 103.

[35] S.Y. Lin, G.R. Wang, G.P. Huang, C.Y. Liu, Electrophoresis 27 (2006) 4257.

[36] T.K. Misra, T.S. Chen, K.T. Wong, C.Y. Liu, J. Chin. Chem. Soc. 52 (2005) 793.

[37] K. Fischer, M. Wacht, A. Meyer, Acta Hydrochim. Hydrobiol. 31 (2003) 134.

[38] M.T. Matyska, J.J. Pesek, A. Katrekar, Anal. Chem. 71 (1999) 5508.

[39] Ph. Schmitt-Kopplin, N. Hertkorn, A.W. Garrison, D. Freitag, A. Kettrup, Anal. Chem. 70 (1998) 3798.

[40] J.J. Lavigne, E.V. Anslyn, Angew. Chem. Int. Ed. 40 (2001) 3118.

[41] B. Dietrich, M.W. Hosseini, J.M. Lehn, R.B. Sessions, Helv. Chim. Acta $66(1983) 1262$. 